\section{Out of space, out of time}

\section{John D. Barrow}

Relativistic Astrophysics. By M. Demiański. Translated by A. Pol. Pergamon: 1985. Pp.34I. f25, \$45.

RELAnivisicle astrophysics means different things to different people. To some it is special relativistic astrophysics with an emphasis upon the physical complexities of high-energy radiation processes, pulsars, accretion disks and neutron stars; to others it means general relativistic astrophysics and the exotic realm of ultrastrong gravitational fields; black holes, gravitational collapse and gravitational waves. Marek Demiański's text is of the general relativistic sort.

The author assumes the student possesses a basic knowledge of general relativity and tensor calculus, the basics of which are completed by page four. The book then commences proper with a succinctly written study of black holes, including a real derivation of the Kerr solution via the Ernst potential and a study of its orbits; derivations of the laws of black hole mechanics and thermodynamics together with simple analyses of the stability of the Kerr and Schwarzschild black hole solutions come later.

Between these discussions of areas which have been of special interest to the author is sandwiched a less compelling section of relativistic hydro- and thermodynamics, with a heavy emphasis on forbut these fall short of the standards set by

\section{Going through the changes}

\section{Rita Cruise $O^{\prime}$ Brien}

Stacking the Chips: Information Technology and the Distribution of Income. By J. Bessant and S. Cole. Frances Pinter, London/Rowman \& Allanheld, 81 Adams Drive, Totowa, New Jersey: 1985. Pp.290. £17.50, \$26.95.

GLITING; beyond the generalities and hyperbole in discussion of the effect of information technology on developing countries has been an uphill struggle. At a recent meeting of the North-South Roundtable (Society for International Development) on this topic, which included leading government spokesmen. scholars and husiness people. it became clear that some progress hald been made. For some yeirs the approach "Information Technology: Blessing or Plague of the Third World" prevailed making it difficult at times to make a sensible contribution.

Central to researching or writing about malism that in subsequently put to little use. But good chapters follow on the stability of isolated self-gravitating bodies in Newtonian and general relativistic gravity with a detailed discussion of the effects of rotation. There are less quantitative surveys of astrophysical processes in the vicinity of black holes and neutron stars other recently published textbooks - in particular that of Shapiro and Teukolsky's Black Holes, White Dwarfs and Neutron Stars (Wiley: 1983).

The final chapter, devoted to cosmology, is very disappointing. Here, the fact that the text was first written in 1978 finally catches up with the publishers. Although the earlier chapters on mathematical aspects of relativistic astrophysics have not dated during the prolonged translation period, the subject of cosmology has been revolutionized to such an extent that the author's discussion of physical processes in the early universe and galaxy formation is seriously out of date. The most recent references in the bibliographies are to works published in 1978 and 1979

As the starting point for a second course on general relativity and its noncosmological applications this book can be recommended to students for its systematic and lucid exposition, but the reader who is interested in contemporary ideas in astrophysics and cosmology will find that the story told by Demiański has been rather overtaken by Old Father Time.

John D. Barrow is a Lecturer at the Astronomy Centre. University of Sussex, Brighton BNI $9 Q H, U K$.

wide range of sectors. The analysis therefore in either scholarly or policy terms is rather unsatisfactory.

They provide a good introduction to the macro-economic literature on informatics and industrialization. employment and the comparative advantages. for example. But it ought to have been set out in a clearer more coherent manner. It is. for example. impossible to make quick reference to tables, which are not well labelled. The authors use a curious character coding which is difficult to follow because the key is to be found on Table 6.2. which is mentioned without giving a page reference. Books ought by first principles to be easily read and understood. And for students. hungry for material on the subject. the splendidly researched literature review is a hesitant and much qualified academic discussion rather than a clear indication of controversy or major contributions to knowledge.

Stacking the Chips works on a model developed by Cole in 1982 which demonstrated that technological change produced significant employment and distributional effects. This book, by its own description. attempts a very crude interpolation of available research evidence. despite Raphael Kaplinsky's warning in Microelectronics and Employment Revisited (ILO, Geneva, 1985) about the major gaps in coverage, methodology and analysis. After reading this latest contribution. I conclude that much indeed still needs to be done.

The conclusion that new technology does not necessarily lead to job destruction in the long term, but that shorter term structural problems are evident, repeats old caveats, many of which were pioneered at the Sussex University Science Policy Research Unit. With the exceptionally broad brief chosen by the authors. the obvious can only be reaffirmed. If in future they are at all interested in studies dealing with fewer technologies, sectors and a more modest terrain than the global economy in eight segments. I look forward to the sequel.

Rita Cruise $O^{\prime}$ Brien is at CSP International. II-15 Wigmore Street, London WIH $9 L B$. UK.

more efficient at international dealing and trading, while destroying many jobs at the clerical level inside the country's banks? The authors of Stacking the Chips however. have opted for comprehensive analysis and refinement of economic modelling on the subject.

The authors did their work at the Sussex University Science Policy Research Unit (a centre of excellent research both on industrialized and developing countries) on a grant from the UN Institute for Training and Research. Ostensibly the book is about the effects of high technology on the distribution of income. The authors obviously felt it necessary to clear a lot of the ground first but instead of then delving more deeply into the subject. they introduce many different variables covering a

\section{New editions}

- Ancient Sedimentary Environments (and their sub-surface diagnosis) 3rd Edn, by R.C. Selley. Publisher is Chapman \& Hall, price is hbk £27.50: pbk £10.95.

- Color Measurement: Theme and Variations 2nd Edn. by D.L. MacAdam. Publisher is Springer-Verlag. price is pbk DM 94.

- Biotechnology: A New Industrial Revolution revised edition. by Steve Prentis. Publisher is Orbis, London, price is $£ 12$.

- Seismic Migration: Part A. Theoretical Aspects 3rd Edn, by A.J. Berkhout. Publisher is Elsevier, price is Dfl. $190, \$ 70.50$. Barron. Publisher is Oxford University Press. price is $£ 60$. This book may be available in the United States, but the publisher has been unable to provide that information.
- Cryogenic Systems 2nd Edn, by Randall F. 